\title{
Unearthing Awareness of Food Heritage Based on Age
}

\author{
Adilah Md Ramli', Dg Khairunisa Ahmad Sapawi', \\ Harifah Mohd Noor ${ }^{2}$, Mohd Salehuddin Mohd Zahari ${ }^{3}$
}

\author{
${ }^{1}$ Faculty of Food Science and Nutrition, ${ }^{2}$ Faculty of Social Science and Humanities, \\ Universiti Malaysia Sabah, Kota Kinabalu, Sabah, Malaysia \\ ${ }^{3}$ Faculty of Hotel and Tourism Management, \\ UniversitiTeknologi MARA Puncak Alam, Selangor, Malaysia \\ m_adilah@ums.edu.my, khairunisa@ums.edu.my, harifah@ums.edu.my, salehuddinm@uitm.edu.my \\ Tel: +60168317565
}

\begin{abstract}
This research explores the understanding of national food heritage based on age ranges (30-35 and > 36 years old). 676 respondents in Klang Valley areas with the appropriate age group and knowledgeable about food heritage are surveyed on a self-completed questionnaire. The correlation of national food heritage differences in terms of preservation, image, identity and sustainabledeterminants $(p<0.05)$ were identified. The key criterion for 'traditional meaning' was selected often with major variations $(p<0.05)$. The diverse interpretation of the age group shows the vision and perception that can be used as a guide to successful approaches to national food heritage.
\end{abstract}

Keywords: Awareness; Food heritage; Age; Klang Valley

eISSN: 2398-4287@ 2020. The Authors. Published for AMER ABRA cE-Bsby e-International Publishing House, Ltd., UK. This is an open-access article under the CC BYNC-ND license (http://creativecommons.org/licenses/by-ncnd/4.0/). Peer-review under responsibility of AMER (Association of Malaysian Environment-Behaviour Researchers), ABRA (Association of Behavioural Researchers on Asians) and CE-Bs (Centre for Environment-Behaviour Studies), Faculty of Architecture, Planning \& Surveying, Universiti Teknologi MARA, Malaysia.

DOI: https://doi.org/10.21834/jabs.v5i17.375 


\subsection{Introduction}

Heritage is a broad concept that encompasses, first of all, tangible assets, including natural and cultural environments, landscapes, historic sites, sites, built environments and monuments. Second, intangible assets consist of collections from past and ongoing cultural practices, knowledge, and life experiences (Ismail, 2016; Bakri, Ibrahim, Ahmad \& Zaman, 2015). Intangible assets would include intangible cultural heritage that refers to non-material objects such as language, music, dance, songs, religion, festivals and food, as well as cultural traditions, activities and customs that have been handed down through generations as part of their daily lives (Tan, Tan, Kook \& Choon, 2018). Traditional food is one of the UNESCO lists, which not only serves as a food heritage but is also an essential part of a strategy that has led to an increase in awareness of food heritage (Di Fiore, 2019). The study aims to examine age-based awareness of the Klang Valley food heritage.

\subsection{Literature Review}

\subsection{Food Heritage in Malaysia}

Wahid, Mohamed, and Sirat (2009) closely linked the food heritage to classic and traditional foods, which are continually prepared and consumed by all generations without any significant alteration to the original flavours. Food heritage can also be reflected in the history, belief, ideology and food technology of society at the time (Bortolotto\&Ubertazzi, 2018). Heritage foods can categorise into two groups. The first group refers to synonymous or common foods that have become part of everyday life. Whereas the second consists of food that faces extinction, that is, food that was once part of a culture but is slowly dying out (Wahid et al., 2009; Raji, Ab Karim, Ishak \& Arshad, 2017).Major concerns and importance are given to maintaining traditional cuisine as it is closely linked to the ingredients, method of cooking, dishes and eating decorum (Choe \& Kim, 2018).

The need for continuing and preserving heritage food is seen as a comparative advantage in maintaining local food culture in the face of external homogenising pressures (Mac, 2018; Shariff, Mokhtar, \& Zakaria, 2008) and in continuing to preserve the creation of valuable products, mainly traditional cuisines (UNESCO, 2008). Endorsement or certification or gazetting is one way to maintain food and culture inherited from the heritage. This initiative revealed the country's awareness and determination to preserve and protect its culinary heritage through certifying sites across the country for their food (Bessiere, 1998). In that context, cultivating awareness of their cultural heritage is the critical factor in driving the local population to protect their heritage.

\subsection{Food heritage and identity}

According to Mooij (2004), understanding culture is what memory is for individuals. It includes common views, behaviours, norms, obligations and values found within a single language speaker living in a similar geographical region within the same historical period. These common subjective components of culture are customarily passed down from generation to 
generation. Cultural awareness is a relevant concept to be considered in shaping social identity. Creating public knowledge and intelligence is also vital because it is known as one of the national identities (Aziz, Mat, \& Halim, 2008).

Traditional cuisine is one of the best examples of cultural heritage in this study, covering the unique aspects of a particular culture in terms of ingredients, preparation methods, dishes or food services. This type of cultural heritage is more difficult to preserve than a physical object because it concerns the values, beliefs, behaviours and norms of society that are difficult to measure, especially among the general public (Shariff et al., 2008).

As a result of growing media communication and interaction, such as anime, popular music and TV drama series, shared identity is emerging in the Asian region, especially among younger generations in many countries, such as Malaysia, Singapore, Thailand, Korea, Japan, Hong Kong, China, Vietnam and Cambodia (Ratnasingam, 2010). By taking one example, Korea has successfully combined its gastronomic culture with its television shows (especially soap operas) which help promote Korean cuisine and its food culture (Kim, Kim, Agrusa, \& Lee, 2012). Such widespread exposure has led to a new and more in-depth understanding of different cultures much faster than any other cause or medium, such as foreign trade, globalisation, migration and tourism (Ratnasingam, 2010). In addition, the public or society must retain the understanding and respect of their cultural heritage in order to create a national identity.

\subsection{Relationship between Age and Food Heritage}

Traditional cuisine is one of the best examples of cultural heritage in this study, covering the unique aspects of culture in terms of ingredients, methods of preparation, dishes or food services. This type of cultural heritage is more difficult to preserve than a physical object because it concerns the values, beliefs, behaviours and rules of society that are difficult to measure, especially among the public (Shariff et al., 2008). In addition, public recognition and knowledge of traditional cuisine have increased in recent years (Hamzah, Ab Karim, Othman, \&Hamzah, 2013; Jalis, Che, \& Markwell, 2014; MD Ramli, Ahmad Sapawi, \&MohdZahari, 2020; Ramli et al., 2019; Sompong\&Rampai, 2015).

In Malaysia, young people are between 15 and 25 years of age (Tamam et al., 2006); young (32 and under) and aged (33 and above) (Sharifah Ezat et al., 2010). The understanding of heritage food is critically important, especially among the young generation (Abdullah et al., 2013). The age groups in this sample are adults (> 36 years of age) and young adults (<35 years of age) (Peterson \& Baez, 2013). Gender typically relates to personality, as it is mostly concentrated in developing adult years relative to early and middle adolescence, where it is still at the point of growth (Schwartz, 2016).

\subsection{Methodology}

This study aims to explore, from a public point of view, the food heritage and its effects on food identity. Furthermore, it focuses on the demographic characteristics of the respondents. The quantitative approach has been used to collect all the relevant details. 


\subsection{Sampling and population plan}

The information needed for this study was collected from 676 respondents in the Klang Valley region using a self-completed questionnaire survey. The target population was the public, consisting of ethnic such as Malay, Chinese, Indian and minor groups. The reason for choosing these ethnic groups was that their food is commonly accepted among Malaysians and is therefore classified as Malaysian food and qualified as heritage food.

The population sample was drawn from the public residents of Klang Valley (LembahKlang), which includes the Federal Territory of Kuala Lumpur, Putrajaya, the Petaling District of Selangor, Gombak, Klang and Hulu Langat and their suburbs and neighbouring cities and towns (Kamaruddin, Osman \& Pei, 2017). In order to gain better insight into the information needed, a set of parameters for potential respondents have been created. Respondents were chosen based on their educational background and should be between 30-35 years and $>36$ years of age and competent on the subject (food heritage).

\subsection{Research instrument}

The survey questionnaire is structured into four major sections. Each section except the demographic background contained items addressing each construct, dimension, or variables to suit the research objectives. Furthermore, each section highlights the used of items in the survey questionnaire, the source of questions and the rationale for their selection. For this study, only section A would be used for the analysis. Section A is created to assess the level of awareness on food heritage looking at the definition, media information, the authority, type, and criteria of food heritage. Five items were adapted and modified from previous researchers (Ramli, Zahari, Halim \&Aris, 2016).

The survey data obtained was tested for reliability and validity. Reliability refers to the extent to which the data collection techniques or analysis procedures will yield consistent findings (Mark, Philip, \& Adrian, 2009). In this study, the researcher employed internal consistency reliability, using Cronbach's Alpha where this type of reliability is used to assess a summated scale where several statements (items) are summed to form a total score for a construct. An acceptable level of reliability indicates that respondents are consistently answering the questions. As for validity, it is concerned whether the findings are what it supposed to be (Mark et al., 2009). Validity is the extent to which a construct measures what it is supposed to measure. In this study, the researcher used academician and nonacademician with a food-related background to validate the content of the items in the survey questionnaire suitability.

In this study, the measurement scale, such as the ordinal and nominal scale was used in developing the survey questionnaire. Nominal scale refers to the usage of the number that allows the researcher to assign subjects to particular categories or groups for identification purposes. The numbers assigned are convenient labels without intrinsic value. The ordinal scale refers to the ranking of the categories in some meaningful way, with some differences among the categories (Sekaran \& Bougie, 2011). 


\subsection{Results}

Test for the reliability of the questionnaire has been done using Cronbach's alpha, with results of 0.837 , which is an acceptable level for this study. The data are then analysed using descriptive analysis such as frequency and percentages. The significance value using chisquare under nonparametric statistic as the data is not normal $(p<0.05)$. Discussion of the result and comparison with past literature would conclude the findings to answer the study's objective.

\subsection{Respondents' profile}

In this study, frequency and descriptive analysis were conducted on the respondent's demographic profile. Table 1 presents the descriptive result of the respondents' profiles. As reported in the table, the majority of respondents were female, at age 30-35 as a young adult $(n=186)$ and $>36$ age as an adult $(n=204)$. Based on ethnicity, the majority were Malay with young adult $(\mathrm{n}=288$ ) and adult $(\mathrm{n}=234)$. In term of professions, the majority were working in the private sector with young adult $(n=137)$ and adult $(n=162)$. As for the educational background, the majority were diploma holders with young adults $(n=244)$ and adults $(n=118)$.

Table1: Demographic background

\begin{tabular}{lll}
\hline $\begin{array}{lll}\text { Demographic } \\
\text { (n=676) }\end{array}$ & Age group & \\
\cline { 2 - 3 } Gender & $30-35$ & $>36$ \\
Male & 152 & 134 \\
Female & 186 & 204 \\
Ethnicity & & \\
Malay & 288 & 234 \\
Chinese & 26 & 52 \\
Indian & 18 & 45 \\
Others & 6 & 7 \\
Profession & & \\
Govermment servant & 129 & 109 \\
Private servant & 137 & 162 \\
Professional & 10 & 28 \\
Student & 52 & 3 \\
Other & 10 & 36 \\
Education & & \\
UPSR & 0 & 4 \\
SRPIPMR & 1 & 21 \\
SPM & 57 & 72 \\
Diploma & 244 & 118 \\
Degree & 36 & 76 \\
Master & 0 & 33 \\
PhD & 0 & 10 \\
Others & 6 & 4 \\
\hline
\end{tabular}

\subsection{Definition of food heritage}

As shown in Table 2, the majority of the active answers to the questions are adults ( $>36$ years of age). 'Traditional food' has been linked to the highest definition of food heritage with a higher response from adult respondents $(n=314)$. They also recognise the heritage of food as 'food passed down from one generation to another,' with $(n=244)$. The third definition chosen by the respondents is 'food-related to cultural context' ( $n=216)$. In addition, 'Sensory 
properties' and 'Commonality' are mostly chosen by the adult age respondents ( $n=191$ and 165).

Table 2: Definition of food heritage based on age group

\begin{tabular}{llllll}
\hline Definition & Rank & $\begin{array}{l}30-35 \\
\mathrm{~N}=338\end{array}$ & Rank & $\begin{array}{l}>36 \\
\mathrm{~N}=338\end{array}$ & $\mathrm{p}$-value \\
\hline Traditional food & 1 & 229 & 1 & 314 & $0.047^{*}$ \\
Food passed down & 2 & 175 & 2 & 244 & 0.000 \\
Related to the cultural background & 3 & 159 & 3 & 216 & 0.000 \\
Celebration & 4 & 143 & 6 & 202 & 0.000 \\
Original ingredients & 5 & 127 & 4 & 209 & 0.000 \\
Authentic cooking method & 6 & 121 & 5 & 208 & 0.000 \\
Sensory properties & 7 & 107 & 7 & 191 & 0.000 \\
Commonality & 8 & 64 & 8 & 165 & 0.000 \\
\hline
\end{tabular}

$N=676{ }^{*}$ Not significant $(p>0.05)$

Meanwhile, 'celebration' with $n=143$, 'original ingredients' with $n=127$ and 'authentic cooking method' with $n=121$ show young adult respondents (30-35 years of age) as their fourth, fifth and sixth definitions of food heritage. Compared to adult respondents, 'Original ingredients' with $n=209$, 'Authentic cooking method' with $n=208$ and 'Celebration' with $n=202$ were the fourth, fifth and sixth definitions of food heritage. For each definition, Table 2 shows significant value. 'Traditional food,' however, is the only definition that has no significant difference $(p>0.05)$ between adults and young adults with $p$-value $=0.047$ by showing that both age categories agree that 'traditional food' is best defined as a food heritage.

\subsection{The Categories of Food Heritage recognition based on age}

Traditional food under Food Heritage list can be divided into nine categories such as ricebased, dessert, gravies and accompaniments, drinks, noodles, appetisers, and cakes. As shown in Figure 1, the most identified food category as food heritage and traditional food is the rice-based category with an overall frequency of $19.87 \%$ with young adults at age 30-35 years old $(n=224)$ and adults at $>36$ years old $(n=187)$.

Followed by 'Dessert' category with $16.34 \%$ of young adults responding more $(n=171)$ than adults ( $n=167)$. Third food category widely affirmed is from 'Gravies and Accompaniments' with $15.9 \%$ preceded by a young adult $(n=178)$ follow by adults $(n=151)$. Drinks category came at fifth-most identified by young adults with $n=147$ and an adult ( $n=116$ ). Despite similar category overall value for 'Noodles' and 'Porridge' categories the identified age from is different from other categories. Like other categories, "Noodles' showed that young adults could be identified more $(n=112)$ and adults $(n=97)$. However, the 'Porridge' category has shown that adults identified more $(n=105)$ than by young adults $(n=104)$. For the last two categories, which are 'Appetiser' with overall $8.02 \%$ and 'Cakes' with overall $6.96 \%$. Appetiser categories with young adult $(n=94)$ and adult $(n=72)$. Lastly, 'Cakes' was identified more by young adults $(n=83)$ than adults $(n=61)$. 


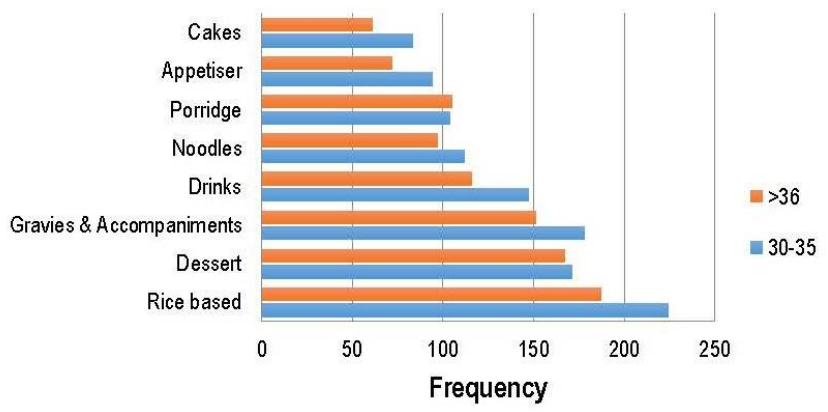

Figure 1: Categories of food heritage recognition

\subsection{Finding information on National Food Heritage}

Based on the finding at Table 3 , both ages use electronic media such as internet, radio or television as for seeking information on National Food Heritage with young adults $(n=189)$ and adults $(n=185)$. Print media such as newspaper, magazine or brochure as their based information with an adult $(n=134)$ and young adult $(n=125)$. It is also showed there is no significant value $(p>0.05)$ between age as their use of both media interchanging.

Table 3: Different type of media with age

\begin{tabular}{llll}
\hline \multirow{2}{*}{ Media } & \multicolumn{3}{c}{ Age } \\
\cline { 2 - 4 } & $30-35$ & $>36$ & P-value \\
\hline Electronic Media & 189 & 185 & \\
Print Media & 125 & 134 & $0.749^{*}$ \\
Others & 17 & 12 & \\
No Answer & 7 & 7 & \\
*Not significant $(p>0.05)$ & & &
\end{tabular}

\subsection{Awareness of the authority responsible}

Findings in Table 4 show that most respondents $(n=365)$ know the authority responsible for endorsing and certifying the National Food Heritage. The adult $(n=208)$ answers correctly than young adult $(n=157)$. There is a significant difference $(p<0.05)$ between both age categories due to their background education. Thus, this affects their knowledge on the matter.

Table 4: Authorities with age

\begin{tabular}{lllll}
\hline & Age & & & \\
Authority & $30-35$ & $>36$ & Total & P-value \\
\hline Department of National Heritage & 157 & 208 & 365 & \\
Wrong Answer & 100 & 63 & 163 & 0.000 \\
Not sure & 78 & 62 & 140 & \\
No Answer & 3 & 5 & 8 & \\
\hline
\end{tabular}




\subsection{Association with national food heritage}

The criteria or determinant associated with National Food Heritage chose by respondents were 'Preservation' $(n=472)$, 'Represent image' $(n=414)$, 'Food identity' $(n=365)$ and 'Sustainability' $(n=307)$. Finding in Table 5 shows that there is a different opinion on criteria associated with National Food Heritage with $p=0.000(p<0.05)$ between adults and young adults. The result also shows that all criteria are adults ( $>36$ years old) as the main respondent compared to young adults (30-35 years old). The adult $(n=271)$ has chosen the first criteria is 'Preservation' as the main association with National Food Heritage compared with young adult $(n=201)$. Secondly, the association of 'Represent image' is chosen mostly by adults $(n=236)$ than young adults $(n=178)$. Next is 'Food identity' with adults $(n=215)$ and young adults $(n=150)$, and lastly is 'Sustainability' with adults $(n=197)$ and young adults $(n=110)$ which response less than half response for both age.

Table 5: Authorities with age

\begin{tabular}{lllll}
\hline \multicolumn{5}{c}{ Age } \\
Criteria's & $30-35$ & $>36$ & Total & P-value \\
\hline Preservation & 201 & 271 & 472 & 0.000 \\
Represent Image & 178 & 236 & 414 & 0.000 \\
Food Identity & 150 & 215 & 365 & 0.000 \\
Sustainability & 110 & 197 & 307 & 0.000 \\
\hline *Not significant $(p>0.05)$ & & &
\end{tabular}

\subsection{The criteria for food heritage}

Respondents have been asked to choose which criteria of traditional food should be considered as heritage.

Table 6: Authorities with age

\begin{tabular}{|c|c|c|c|c|}
\hline \multirow[b]{2}{*}{ The criteria } & \multicolumn{4}{|c|}{ Age } \\
\hline & $30-35$ & $>36$ & Overall & $\mathrm{P}$-value \\
\hline Historical value & 189 & 249 & 438 & 0.000 \\
\hline Traditional value & 268 & 296 & 564 & 0.004 \\
\hline Authentic flavour & 208 & 246 & 454 & 0.002 \\
\hline Food presentation & 94 & 154 & 248 & 0.000 \\
\hline Variety & 64 & 128 & 192 & 0.000 \\
\hline Convenience & 30 & 98 & 128 & 0.000 \\
\hline Commonalities & 28 & 94 & 122 & 0.000 \\
\hline Originality & 225 & 279 & 504 & 0.000 \\
\hline Staple food ingredients & 82 & 189 & 271 & 0.000 \\
\hline Sensory properties & 72 & 160 & 232 & 0.000 \\
\hline Cooking method & 170 & 197 & 367 & 0.037 \\
\hline Food Innovation & 40 & 107 & 147 & 0.000 \\
\hline Technology & 25 & 101 & 126 & 0.000 \\
\hline Cross-culturing & 75 & 142 & 217 & 0.000 \\
\hline
\end{tabular}

${ }^{*}$ Not significant $(p>0.05)$ 
Table 6 shows that the overall value of respondents choosing 'Traditional value' is higher than other criteria with adults $(n=296)$ and young adults $(n=268)$. 'Originality' criteria, which placed at second, with adults $(n=279)$ and young adults $(n=225)$. Third highest is 'Authentic flavour' with adults $(n=246)$ and young adults $(n=208)$. Then, 'Historical value' with adults $(n=249)$ and young adults $(n=189)$. The final criteria are 'Cooking method' with adults $(n=197)$ and young adults $(n=170)$. All criteria are being analysed and shown that there is a significant difference $(p<0.05)$ between adults (>36 years old) and young adults $(30-35$ years old).

\subsection{Discussion}

In this context, in Malaysia, the demographic background plays a role in representing and defining a country, mainly when dealing with the identification and redefinition of food heritage towards national identity. Previous research has shown that demographics play a role in defining identities across cultures and countries (Ramli et al., 2016; MD Ramli et al., 2020).

Both age group, adult (>36 years old) and young adult (30-35 years old) gave a different opinion regarding food heritage definition except for 'traditional food'. Sebastia (2016) mentioned that the common belief in traditional food often invokes cultural heritage, in which involves traditional knowledge. The know-how shared and transmitted by word-of-mouth among small and big groups such as family, clan territory, country or geographical region covering several countries (Petronela, 2016). Wahid et al. (2009) classified food heritage as classical and traditional foods which are prepared by all generation without changing its flavour, taste and familiar to the locals. Hence, traditional food tends to be well-recognised by all ages as the practice of imparting the knowledge of its preparation remains in current society. However, Hamzah et al. (2015) stated that most youth knows on traditional food but do not acquire the respective preparation skills.

Traditional food listed under National Food Heritage is accepted as representative of Malaysian food as part of country Gastronomic Culture (Leong et al., 2012). It is indicated that young adults are more knowledgeable on foods that considered as heritage. However, Hairon, Zahari, Akbarruddin, \& Majid (2017) statement on young people's eating habits tends to try new things and avoiding mainstream food. The continuous change is inevitable in the formation of social identity, especially among youth who undergo the most critical period in their lives. This phase of youth identity formation is associated with the greatest level of experimentation as well as openness to external influences such as the immediate social environment and the cyber world which is popular with young people (Ratnasingam, 2010). Young generation eating habits show a tendency to try new thing and to experience it with their friends, family, and peers (Hairon et al., 2017; Hamzah et al., 2015). Noor, Zakaria, Shahril, Hadi, \&Zahari (2013) state that age plays an essential role in knowledge and ability to provide relevant information. As for the older age group, they are committed to specific ways of life and generally more suspicious and resistant to new things. These past literature conflict with the findings. There would be other factors that influence young adult awareness on food heritage, such as information finding such as electronic and printed media. 
Media play an important role in gathering information from across the globe, which provides with a range of option that requires them to make choices based on their values and priorities (O'Kane, 2016). Most adults use electronic media to create or post their cultural heritage experiences whereas, for young adults, the heritage institution may need a precise tool and personal type of media to engage with the heritage (Amestoy, 2013), as youth have their cultural patterns and values which can be influenced by a variety form of mass media (Hamzah et al., 2015). There is a disconnection of the young generation with their cultural background due to lack of communication and knowledge from the older generation about their cultural legacies and histories (Alden, 2011). To preserve food heritage, the involvement of young generation in preparation of traditional food is essential, which is possible through festivals and celebration with the guidance from the older generation especially in transferring knowledge and continuous practice (Noor et al., 2013).

Food heritage is emphasised as part of the nation's intangible cultural heritage whereby the Department of National Heritage under the Ministry of Tourism and Culture Malaysia responsible for determining and registered intangible and tangible cultural heritage (Mustafa et al., 2013). It shows that food act as a marker or identity of individuals or community (Eum, 2008), especially food that is already recognised as heritage. Youth can be represented as the mediator of culture through sustaining heritage as well as an asset to preserve the heritage food from rapid globalisation (Hamzah et al., 2015).

\subsection{Conclusion}

The findings show that there is a gap between adults and young adults in answering food heritage awareness questions based on food heritage description, food heritage list, media information, and authority, association and food heritage criteria. All the results show that adults (> 36 years of age) respond to all questions and engage more than young adults (3035 years of age). In general, different understanding between young people and adults can be used as a key factor for government or stakeholders to establish a practical framework for preserving conventional food in the face of homogenising forces from outside the world, such as globalisation.

The tendency of young people to keep up with new trends has led to a change in traditional foods in line with modern preferences. This alters the use of ingredients, their sensory qualities, cooking methods and preparation techniques that can mislead the perception of authenticity in the kitchen. In addition to globalisation, rapid urbanisation of the country is also seen as one of the pressures to sustain the food heritage and its practices.

The majority of young adults migrate to urban areas to work, so most of them leave traditional food practices at home and choose convenience to accommodate their busy lifestyles. Urbanisation also endangers the natural sources of indigenous ingredients or materials that are essential components for the flavouring or preparation of traditional food. This will eventually contribute to the elimination of certain traditional foods in the culture. Using outlets such as the internet and social media that are popular with young adults in disseminating knowledge of local cuisine, and developing a platform that matches adult 
interests, would create awareness of the nation's food heritage across all ages to reinforce the nation's identity.

\section{References}

Abdullah, K. M., Muhammad, R., Zahari, M. S. M., \& Sharif, M. S. M. (2013). Approach of Malay food preparation terminologies among young Malay culinarians. Procedia-Social and Behavioral Sciences, 105, 410-417.

Alden, D. (2011). A Fading Tradition: Design as a Portal to The Discovery of One's Own Cultural Heritage. Iridescent, 1(2), 64-73.

Amestoy, V. A. (2013). Demand for cultural heritage Handbook on the economics of cultural heritage: Edward Elgar Publishing.

Aziz, W. A. W. A., Mat, A. C., \& Halim, M. A. S. A. (2008). Semiotic Knowledge Towards Heritage Product in Tourism Industry: A Case of Terengganu. Paper presented at the Thrusting Islam, Knowledge and Professionalism in ECER Development, 1st ECER Regional Conference (ERC) 2008, Renaissance Hotel, Kota Bharu, Kelantan, Malaysia.

Bakri, A. F., Ibrahim, N., Ahmad, S. S., \& Zaman, N. Q. (2015). Valuing built cultural heritage in a Malaysian urban context. Procedia-Social and Behavioral Sciences, 170, 381-389.

Bessiere, J. (1998). Local Development and Heritage: Traditional Food and Cuisine as Tourist Attractions in Rural Areas. SociologiaRuralis, 38(21-34).

Bortolotto, C., \&Ubertazzi, B. (2018). Foodways as Intangible Cultural Heritage. International Journal of Cultural Property, 25(4), 409-418.

Choe, J. Y. J., \& Kim, S. S. (2018). Effects of tourists' local food consumption value on attitude, food destination image, and behavioral intention. International Journal of Hospitality Management, 71, 1-10.

Di Fiore, L. (2019). Heritage and food history. Food Heritage and Nationalism in Europe. London: Routledge, Taylor \& Francis Group.

Eum, I. (2008). A Study on Current Culinary Culture and Religious Identity in the Gulf Region. International Area Review, 11(2), 55-73.

Hairon, S., Zahari, M. S. M., Akbarruddin, M. N. A., \& Majid, H. N. A. (2017). Overview of Hipster food culture development in Malaysia. Journal of Tourism, Hospitality \& Culinary Arts, 9(2), 481-492.

Hamzah, H., Ab Karim, M. S., Othman, M., \& Hamzah, A. (2013). Dimensions of Authenticity in Malay Cuisine from Experts' Perspectives. Academic Journal of Interdisciplinary Studies, 2(3), 369.

Hamzah, H., Karim, M. S. A., Othman, M., Hamzah, A., \& Muhammad, N. H. (2015). Challenges in Sustaining the Malay Traditional Kuih among Youth. International Journal of Social Science and Humanity, 5(5), 472-478.

Ismail, W. H. W. (2016). Young visitors in the city: Their perceptions of heritage buildings. Procedia-Social and Behavioral Sciences, 234, 470-477.

Jalis, M. H., Che, D., \& Markwell, K. (2014). Utilising local cuisine to market Malaysia as a tourist destination. Procedia-Social and Behavioral Sciences, 144, 102-110. 
Kamaruddin, R., Osman, I., \& Pei, C. A. C. (2017). Customer expectations and its relationship towards public transport in Klang Valley. Journal of ASIAN Behavioural Studies, 2(4), 29-39.

Kim, S., Kim, M., Agrusa, J., \& Lee, A. (2012). Does a Food-themed TV Drama Affect Perceptions of National Image and Intention to Visit a Country? An Empirical Study of Korea TV Drama. Journal of Travel \& Tourism Marketing, 29(4), 313-326.

Leong, Q. L., Othman, M., MohdAdzahan, N., \& Ab. Karim, M. S. (2012). A Model of Malaysian Food Image Component: Toward Building a Sustainable Tourism Product. PERTANIKA Journal Social Sciences \& Humanities, 20(2), 299-315.

Mac Con lomaire, M. (2018). Recognising food as part of Ireland's intangible cultural heritage. Folk Life, 56(2), 93115.

Mark, S., Philip, L., \& Adrian, T. (2009). Research Methods For Business Students. Harlow: Prentice-Hall.

MD Ramli, A., Ahmad Sapawi, D. K., \&MohdZahari, M. S. (2020). The determinants of food heritage based on age in Klang Valley, Malaysia. Journal of Tourism, Hospitality \& Culinary Arts (JTHCA), 12(1), 1-16.

Mooij, M. d. (2004). Consumer Behaviour and Culture, Consequences for Global Marketing and Advertising. London: Sage Publications, Inc.

Mustafa, N. A., \& Abdullah, N. C. (2013). Preservation of cultural heritage in Malaysia: An insight of the National Heritage Act 2005. Paper presented at the Proceedings of International Conference on Tourism Development, February.

Noor, S. M., Zakaria, N. A., Shahril, N. M., Hadi, H. A., \&Zahari, M. S. M. (2013). PulutKuning in Malay Society: The Beliefs and Practices Then and Now. Asian Social Science, 9(7).

O'Kane, G. (2016). A moveable feast: Contemporary relational food cultures emerging from local food networks. Appetite, 105, 218-231.

Peterson, P. E., \& Baez, R. J. (2013). Oral Health Surveys: Basic Methods (5 ed.). France: World Health Organization.

Petronela, T. (2016). The importance of the intangible cultural heritage in the economy. Procedia Economics and Finance, 39, 731-736.

Raji, M. N. A., Ab Karim, S., Ishak, F. A. C., \& Arshad, M. M. (2017). Past and present practices of the Malay food heritage and culture in Malaysia. Journal of Ethnic Foods, 4(4), 221-231.

Ratnasingam, M. (2010). National Identity: A Subset of Social Identity? InEthnic Relations and Nation Building: The Way Forward (pp. 3-34). Petaling Jaya, Selangor, Malaysia: Strategic Information and Research Development Center.

Ramli, A. M., Zahari, M. S. M., Halim, N. A., \& Aris, M. H. M. (2016). The Knowledge of Food Heritage Identithy in Klang Valley, Malaysia. Procedia - Social and Behavioral Sciences, 222, 518-527.

Ramli, A. M., Sapawi, D. K. A., \&Zahari, M. S. M. (2019). The Significant of Food Heritage Endorsement in Building Food Identity. Environment-Behaviour Proceedings Journal, 4(12), 231-238.

Schwartz, S. J. (2016). A New Identity for Identity Research. Journal of Adolescent Research, 20(3), 293-308. 
Md Ramli, A., et.al. / Journal of ASIAN Behavioural Studies (jABs), 5(17) Sep / Dec 2020 (pp.41-53)

Sébastia, B. (2016). Eating traditional food: politics, identity and practices Eating Traditional Food (pp. 15-33): Routledge.

Sekaran, U., \& Bougie, R. (2011). Research Method For Business: A Skill Building Approach: Taylor \& Francis.

Shariff, N. M., Mokhtar, K., \& Zakaria, Z. (2008). Issues in the Preservation of Traditional Cuisines: A Case Study in Northern Malaysia. International Journal of the Humanities, 6(6).

SharifaEzat, W. P., Jamsiah, M., Malka, S. A., Azimatun Noor, A., Tuti, N., \& Noor Izzah, A. S. (2010). Customers' satisfaction among urban and rural public health clinics in state of Selangor, Malaysia. Malaysian Journal of Public Health Medicine, 10(2), 52-67.

Sompong, N., \&Rampai, N. (2015). Knowledge management of Thai local food on the route of northern tourism in Thailand. International Journal of Information and Education Technology, 5(9), 664.

Tan, S. K., Tan, S. H., Kok, Y. S. \& Choon, S. W. (2018). Sense of place and sustainability of intangible cultural heritage-The case of George Town and Melaka. Tourism Management, 67, 376-387.

Tamam, E., Idris, F., Tien, W. Y. M., Hamzah, A., \& Hamzah, R. (2006). News media socialisation and ethnic tolerance among youth in Malaysia. In 15th AMIC Annual Conference Organised by The Asian Media Information and Communication Center (pp. 17-20).

UNESCO. (2008). World Heritage Information Kit. France: UNESCO World Heritage Center. Retrieved from http://whc.unesco.org.

Wahid, N. A. (2009). Heritage Food Tourism: Bahulu Attracts? Paper presented at the 2nd National Symposium on Tourism Research: Theories and Application, UniversitiSains Malaysia, Pulau Pinang. 